\title{
PUNCAK-PUNCAK CAPAIAN SUFISTIK DALAM PERSPEKTIF METODOLOGIS
}

\author{
Oleh: \\ Tasmin Tangngareng \\ Jurusan/Prodi Ilmu Hadis \\ Fakultas Ushuluddin dan Filsafat \\ UIN Alauddin Makassar \\ E-mail: tasmin.tangngareng64@gmail.com
}

\begin{abstract}
Abstrak
Tulisan ini mengkaji tentang puncak-puncak sufistik dalam perspektif metodologis. Ajaran tasawuf pada hakekatnya adalah ekspresi keagamaan, ia merupakan komitmen moral dan iman dari orang-orang yang beragama secara saleh. Hal ini disebabkan, tasawuf dan ajarannya berfungsi untuk mewadahi dan menstabilkan komitmen moral orang yang beriman sehingga tasawuf memberikan tempat bagi kehidupan rohaniyah. Dengan rohani yang suci dan bersih, sang sufi memungkinkan dirinya untuk sampai pada puncak-puncak capaian sufistik, yakni mengadakan komunikasi, bahkan "menyatu" (ittihad) dengan Tuhannya. Dalam menggapai puncak-puncak capaian sufistik itu, memerlukan proses perjalanan yang sangat panjang dan melelahkan, karena harus melalui berbagai maqam dan hal.. Maqam adalah suatu tahap pencapaian ruhaniah dalam mendekat kepada Tuhan, yang merupakan hasil upaya bagi seorang sufi; sedangkan hal adalah suasana batiniah, yang senantiasa mengitari perasaan calon sufi dalam setiap maqam yang selalu bergerak naik setahap demi setahap sampai ke tingkat puncak perjalanannya yakni puncak capaian sufistik. Metode perjalanan kepuncak capaian sufistik memiliki tingkat yang beragam, yakni mahabbah, ma'rifah, ittihad, hulul dan wahdat al-wujud. Untuk sampai pada tingkat-tingkat tersebut berbagai metodologis yang dilakukan para sufi. Dalam hal ini, metode yang dilakukan untuk sampai pada tingkat mahabbah dan ma'rifah adalah qalb - ruh - sirr. Sedangkan metode yang dilakukan untuk sampai pada tingkat itihad, hulul dan wahdat alwujud adalah al-fana dan al-baqa.
\end{abstract}

Keywords:

Tasawuf, Sufistik, Qalb, Ruh, Sir.

\section{PENDAHULUAN}

Menurut al-Qur`an, manusia terdiri dari dua unsur, yaitu jasmani (materi) dan rohani (immateri). ${ }^{1}$ Dari segi hubungannya, unsur materi memiliki hubungan

\footnotetext{
${ }_{2}^{1}$ Lihat QS. Al-Hijr (15): 28-29; QS. Al-Sajadah (32): 8-9.

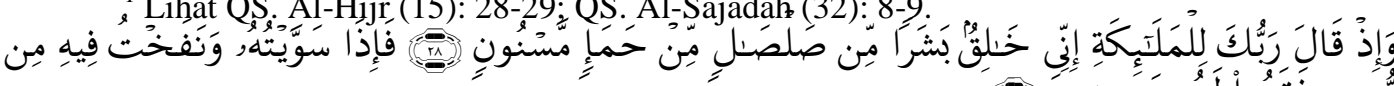

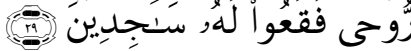
Terjemahnya:

Dan (ingatlah), ketika Tuhanmu berfirman kepada para malaikat: "Sesungguhnya Aku akan menciptakan seorang manusia dari tanah liat kering (yang berasal) dari lumpur hitam yang diberi bentuk. Maka apabila Aku Telah menyempurnakan kejadiannya, dan Telah meniup kan kedalamnya ruh (ciptaan)-Ku, Maka tunduklah kamu kepadanya dengan bersujud.
} 
yang jauh dari Allah, sedangkan unsur rohani atau immateri memiliki hubungan yang dekat dengan Allah. Oleh sebab itu, ruh memiliki posisi yang sangat subtansial dan dominan dalam menentukan karakter manusia. Kebahagiaannya mengungguli kebahagiaan jasmani, kenikmatan yang dirasakan pun mendominasi kenikmatan yang dirasakan oleh jasmani.

Sehubungan dengan hal tersebut, maka dengan metoda self manajement ala tasawuf atau sufisme ${ }^{2}$ sebagai pilihan yang tepat untuk menjadikan manusia bersikap mental dan berkepribadian rohani. Sebab, pada hakikatnya jalan tasawuf akan melahirkan suatu tenaga yang maha ampuh menjaga manusia untuk tetap dalam keseimbangan rohaniah dalam menghadapi setiap desakan kehidupan yang keras. Pada sisi lain, tasawuf selalu mendorong pengawasan melekat sehingga ia tidak pernah berhenti berusaha menciptakan kualitas manusia yang berakhlak sebagai makhluk Tuhan, sebagai makhluk individu dan sebagai makhluk sosial, adalah obsesi tasawuf.

Tasawuf, ${ }^{3}$ sebagai paham dalam Islam dan sebagai salah satu tipe mistisisme, merupakan masalah ekslusif dan transkultural dalam Islam. Disebut demikian karena masalah sufisme dalam tinjauan pluralitas ajaran Islam di masa Nabi tidak ada. Namun bagaimanapun, soal sufisme adalah soal manusia yang

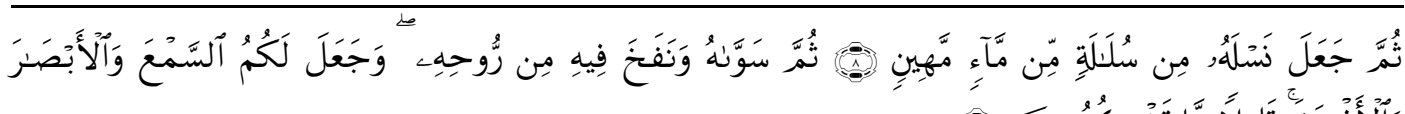

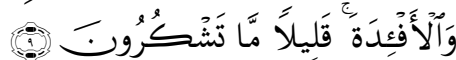

Terjemahnya:

Kemudian dia menjadikan keturunannya dari saripati air yang hina. Kemudian dia menyempurnakan dan meniupkan ke dalamnya roh (ciptaan)-Nya dan dia menjadikan bagi kamu pendengaran, penglihatan dan hati; (tetapi) kamu sedikit sekali bersyukur.

2 Term atau istilah sufisme ditujukan secara khusus kepada orang-orang Islam yang mendalami mistisisme, yakni dunia tasawuf. Dengan demikian, kata sufisme tidak dipakai untuk mistisisme yang terdapat dalam agama-agama lain. Tasawuf atau Sufisme mempunyai tujuan memperoleh hubungan langsung dan disadari dengan Tuhan, sehingga disadari benar bahwa seseorang berada di hadirat Tuhan. Intisari dari mistisisme, termasuk di dalamnya sufisme ialah kesadaran akan adanya komunikasi dan dialog antara roh manusia dengan Tuhan dengan mengasingkan diri dan berkontemplasi. Kesadaran berada dekat dengan itu dapat mengambil bentuk ittihad (bersatu dengan Tuhan ). Lihat Harun Nasution, Falsafat dan Mistisisme dalam Islam (Cet. VII; Jakarta: Bulan Bintang, 1990) , h.56

${ }^{3}$ Dalam mendifinisikan term tasawuf hampir tidak terbantahkan, karena ia berpangkal pada esensi tasawuf sebagai pengalaman rohaniah yang hampir tidak mungkin dijelaskan secara tepat melalui bahasa lisan, karena masing-masing orang yang mengalaminya mempunyai penghayatan yang berbeda dari orang lain sehingga dalam pengungkapannya juga melalui cara yang berbeda. Sehingga, batasan-batasan tasawauf sangat bervariasi. Tidak mengherangkan pula, jika penulis-penulis banyak merelevansikan term tasawuf dengan term; (1) Safa dalam arti suci dan sufi adalah orang yang disucikan; (2) saf, yang terinterpretasi dari posisi baris pertama dalam shalat, dimana para sufi senantiasa menempati posisi tersebut; (3) ahl al-Suffah, yaitu para sahabat yang hijrah bersama Nabi saw dengan meninggalkan harta kekayaannya. Kehidupan mereka sangat miskin dan tinggal di Mesjid Nabi (Masjid Nabawy), tidur di atas bangku batu dengan memakai suffah (pelana) sebagai bantal. Walaupun kondisinya demikian, namun Ahl al-Suffah ini berhati mulia dan tidak mementingkan dunia, sebagaimana yang dialami oleh kaum sufi; (4) Sophos (bahasa Yunani) yang berarti hikmah dimana perolehan hikmah tersebut senantiasa dialami oleh kaum sufi; (5) suf yakni kain wol yang kasar dan kusut yang melambangkan kesederhanaan kaum sufi, karena mereka menghindarkan diri dari kemewahan dan keistimewaan dunia. Lihat Abu Bakar Muhammad al-Kalabazi, al-Ta'aruf li Mazhab Ahl alTasawuf (Kairo: Maktabat al-Kulliyat al-Azhariyah, 1969), h. 28-29; Harun Nasution, " Falsafat dan Mistisisme", op.cit., h. 56-57; hemat penulis, kesemua term tersebut di atas dapat dijadikan acuan sebagai asal-asul batasan tasawuf. Namun, term yang terakhir sangat pantas dijadikan sebagai pegangan, karena mengingat pola hidup kesufian terpokus pada ke-sederhanaan dengan lambang "wol kasar" yang perealisasiannya mereka menjauhkan diri dari kesenangan dunia. 
asasi. Soal umat Islam yang problematis, diaklektis dan humanis yang menyangkut etos pandangan dan implikasinya pada insight kepada Tuhan. Tujuannya adalah mendekatkan diri sedekat mungkin dengan Tuhan, sehingga Ia dapat terlihat dengan mata hati bahkan roh seseorang dapat bersatu dengan Roh Tuhan.

Dalam ajaran Islam diketahui bahwa Tuhan memang dekat sekali dengan manusia, QS. al-Baqarah (2): 186. Bahkan, Tuhan dapat mengambil tempat dalam diri manusia, QS. Qaf (50): 16. Karena itu, kaum sufi dalam mencari Tuhan tidak perlu pergi jauh; cukup ia masuk ke dalam dirinya dan Tuhan yang dicarinya akan dijumpai dalam dirinya sendiri. Dengan konteks inilah dapat dipahami bahwa kaum sufi mampu bermanunggal dengan Tuhan, dan ketika hal yang demikian terwujud maka sungguh ia telah berada pada puncak-puncak capaian sufistik. Metode yang ditempuh seseorang untuk sampai ke puncak-puncak capaian sufistik, demikian panjang dan berliku. Bahkan keadaan yang dialami ketika ia sudah sampai ke puncak tersebut sangat bervariasi dan beragam. Oleh karena, rasa dan rihlah rohaniyah (perjalanan bathiniyah) mereka berbeda-beda.

\section{METODE PERJALANAN SUFI DALAM MENDEKATKAN DIRI KEPADA TUHAN}

Metode perjalanan yang ditempuh seseorang untuk sampai pada puncak kesufian memiliki stasion-stasion (tingkatan-tingkatan) yang dalam istilah sufi disebut maqamat, yakni tempat seorang calon sufi menunggu sambil berusaha keras untuk membersihkan diri agar dapat melanjutkan rihlah ilahiyah (perjalanan ilahiyah) yang berat dan sulit ke tingkatan berikutnya.

Walaupun para sufi berbeda-beda dalam mengurut pola dan proses perjalanan maqamat, ${ }^{4}$ namun yang lazim dilakukannya adalah tahapan-tahapan sebagai berikut :

1. Taubat (التوبة)

${ }^{4}$ Maqamat adalah bentuk jamak dari maqam. Maqam secara literal berarti tempat berdiri, stasion tempat, lokasi, posisi atau tingkatan. Secara terminologis berarti kedudukan spritual. Lihat Media Zainul Bahri, Menembus Tirai Kesendiriannya Mengurai Maqamat da Ahwal Dalam Tradisi Sufi (Cet. I; Jakarta: Prenada, 2005 ), h.30; Dalam al-Qur`an, kata maqam yang berarti tempat, disebutkan beberapa kali yang mengandung makna abstrak (bersifat spritual) dan konkret ( bersifat fisik dan leteral) misalnya QS. AlBaqarah (2): 125; al-Isra (17). 79; QS. Maryam (19);73. QS. Al-Safat (37). 164. QS. Al-Dukhan (44).51. QS al-Rahman 55). 46. Selanjutnya para sufi tidak selamanya memberikan angka dan susunan yang sama tentang stasion-stasion yang harus dijalani oleh setiap orang untuk sampai ke tingkat sufi. Misalnya saja, Muhammad al-Kalabadi dalam menyusun stasion-stasion secara sistematis yang dimulai dari taubat, zuhud, sabar, kefakiran, kendahan hati, takwa, tawakkkal, kerelaan, cinta, ma'rifah. Sementara itu, Abu Nasr al-Sarraj alTusi menyusun stasion-stasion-nya yang dimulai dari tawbat, wara', zuhud, kefakiran, sabar, tawakkkal, kerelaan hati. Adapun al-Gazali, ia menyusun stasion-stasion tersebut dimulai dari tawbat, sabar, kefakiran, zuhud, tawakkkal, cinta, ma'rifah, kerelaan.. Sedangkan Abu Qasim al-Qusyairi menyusun stasion-stasion tersebut dimulai dari tawbat, wara' zuhud, tawakkkal, sabar, kerelaan. Liaht Harun Nasution, op. cit., h. 6263; Ali ibn Usman al-Jullabi al-Hujwiri, Kasyf al-Mahjub: Risalah Persia Tertua Tentang Tasawuf, Terj. Abdul Hadi WM. (Bandung: Mizan, 1993), h. 90

${ }^{5}$ Taubat berakar dari kata taba yang berarti kembali. Orang yang bertaubat kepada Allah swt., adalah orang yang kembali dari sesuatu menuju sesuatu; kembali dari sifat-sifat tercela menuju sifat-sifat terpuji, kembali dari larangan Allah menuju perintahnya, kembali dari maksiat menuju taat, kembali dari segala yang dibenci Allah menuju yang diredainya, kembali dari yang saling bertentangan menuju yang saling menyenangkan, kembali kepada Allah setelah meninggalkannya dan kembali taat setelah menentangnya. Lihat 
Stasion pertama dalam tasawuf adalah tobat dari dosa-dosa, kemudian menghindarkan diri dari perbuatan makruh dan selanjutnya dari perbuatan syubhat. Tobat yang dimaksud adalah tawbah nasuha, yaitu tobat yang membuat orangnya menyesal atas dosa-dosanya yang lampau dan betul-betul tidak akan berbuat dosa lagi walau sekecil apapun.

Bagi sufi, fungsi tobat bukan hanya menghapus dosa, tetapi lebih dari itu, yaitu sebagai syarat mutlak agar dapat dekat dengan Tuhan. ${ }^{6}$ Karena itu, salah satu amalan yang harus dilakukan dalam stasion pertobatan adalah ber-istigfar minimal seratus kali dalam sehari agar ia bersih dari dosa. ${ }^{7}$ Jelaslah bahwa stasion pertobatan ini memakan waktu yang panjang dan untuk memantapkan tobatnya, maka calon sufi melanjutkan perjalannya ke stasion zuhud.

\section{Wara' (الورع) ${ }^{8}$}

Stasiun wara' dalam dunia sufi menunjuk kepada pola hidup dan kehidupan dengan selalu waspada dalam berbuat. Dengan kata lain, calon sufi yang berada dalam stasiun wara' senantiasa menghindarkan diri dari penggunaan sesuatu yang tidak jelas statusnya, apalagi yang jelas-jelas haram.

Pola hidup wara' menurut perpekstif sufi terdiri atas dua macam, yakni; wara' lahiriyah dalam arti tidak mempergunakan anggota tubuh untuk hal-hal-hal yang tidak diridhahi Tuhan; dan wara' bathiniyah dalam arti tidak menempatkan atau mengisi hati sesuatupun kecuali Tuhan. ${ }^{9}$ Jelaslah bahwa dalam stasion wara' ini, para calon sufi harus berusaha menghindarkan diri dari perbuatan-perbuatan syubhat.

Jadi, wara berarti meninggalkan segala yang tidak bermanfaat berupa ucapan, penglihatan, pendengaran, perbuatan, ide atau aktivitas lain yang dilakukan seorang muslim. Semua itu, bila tidak memberi manfaat, tidak akan dilakukannya.

Muhammad Ibn `Alan al-Shiddiqiy, Dalil al-Falihin li Thuruq Riyadh al-Shalihin ( Riyadh: Dar al-Ifta, tth), h. 78; Selanjutnya dalam pendifinisan tobat, para sufi berbeda pendapat, tetapi pada garis besarnya dapat dibedakan kepada tiga ketgori, yakni; Pertama, tobat dalam pengertian meninggalkan segala kemaksiatan dan melakukan kebajikan secara terus menerus; Kedua, tobat dalam pengertian keluar dari kejahatan dan memasuki kebaikan karena takut pada murkah Allah; Ketiga, tobat dalam pengertian terus menerus bertobat walaupun sudah tidak pernah lagi berbuat dosa (tobat abadi). Lihat Rivay Siregar, Tasawuf; dari Sufisme Klasik ke Neo-Sufisme, (Cet. II; Jakarta: PT. RajaGrafindo Persada, 2000), h. 115; bandingkan dengan Imam alGazali, Muqasyafah al-Qulub al-Muqarib ila Hadhrah 'Allam al-Ghuyub fi 'Ilm al-Tasawwuf, diterjemahkan oleh Irwan Kurniawan dengan judul “ Menyingkap Hati Menghampiri Ilahi Ziarah Ruhani Bersama Imam alGazali'( Cet. III; Bandung: Pustaka Hidayah, 2000), h. 37

${ }^{6}$ Dalam QS. al-Baqarah (2): 222 Allah berfirman إن الله يحب التوابين ويحب المتطهرين . Dengan bergandengnya term al-tawwabin dengan al-mutathahhirin pada ayat tersebut mengidikasikan bahwa apabila seseorang ingin mendekatkan diri kepada-Nya, maka ia harus membersihkan dirinya lahir dan batin dari noda dan dosa, karena Allah Maha Suci dan menyukai yang suci.

${ }^{7}$ Lihat Rivay Siregar, op. cit., h. 116. Perintah ber-istigfar dalam pola fi'l amr ditemukan dalam Alquran sebanyak 19 kali. Lihat Muhammad Fu'ad Abd. Al-Baqy, al-Mu'jam al-Mufahras Li Alfaz al-Qur'a, (Indonesia: Maktabah Dahlan, tt.h), h. 635-636. Di samping itu, ditemukan pula perintah untuk ber-istigfar yang disertai dengan perintah bertobat sebagaimana yang termaktub dalam QS. Hud (11): 3, 52 dan 61.

${ }^{8}$ Secara literal wara berarti menjauhkan diri dari dosa dan menahan diri dari hal-hal yang syubhat dan maksiat. Lihat Louis, al-Munjid fi al-Lughah wa al-A lam (Beirut: Dar al-Masyriq, 1984), h. 896. Dalam perspektif para sufi adalah meninggalkan segala seuatu yang tidak jelas hukumnya, baik yang menyangkut makanan, pakaian maupun persoalan. Lihat Rivay Siregar, op. cit., h. 118.

${ }^{9}$ Lihat Qamar al-Kailani, Fiy al-tasawwuf al-Islam (Kairo: Dar al-Ma'arif, 1976), h. 61 
Karena itu, orang yang bersikap wara adalah yang terus berusaha agar setiap ucapannya memberi manfaat bagi diri sendiri atau orang lain.

\section{Faqr (الفقر ${ }^{10}$}

Stasion faqr dalam dunia sufi menunjuk kepada pola hidup kemiskinan yang berdimensi material. ${ }^{11}$ Bagaimanapun konotasi yang diberikan masing-masing sufi mengenai al-faqr, namun pesan yang tersirat di dalamnya adalah agar manusia bersikap hati-hati terhadap pengaruh negatif yang diakibatkan oleh keinginan kepada harta kekayaan. Karena itu, bagi calon sufi yang berada dalam stasion ini merasa lebih baik kebutuhan hidupnya hanya sedikit dan ia tidak meminta kecuali hanya untuk dapat menjalankan kewajiban-kewajiban agama.

Oleh karena itu, dalam tasawuf, faqr berarti senantiasa merasa butuh kepada Allah swt. Seorang hamba menyatakan diri tidak memiliki sesuatu, bebas dari jenis keterkaitan kepada hal-hal duniawi, merasakan kebutuhan dan ketidakberdayaan dihadapan Allah. Jadi, faqr bukan orang yang tidak punya bekal hidup, tapi orang yang bersih atau kosong hatinya dari keinginan duniawi.Ini juga bermakna bahwa faqr itu adalah orang yang memperkaya rohani atau batinnya dengan Allah swt.

\section{Zuhud (الز هد) ${ }^{12}$}

Stasion zuhud dalam dunia sufi menunjuk kepada pola hidup yang bersih dari dosa dengan cara meninggalkan dunia materi. Karena itu, pada stasion kedua ini (zuhud), para calon sufi harus melepaskan segala macam kenikmatan dunia dan keindahan hidup yang bersifat materi. Dengan kata lain, ia harus terbebas dari ikatan materi agar ia bebas dan leluasa mengkhususkan diri dalam beribadah kepada Tuhan.

Mengenai pola hidup ke-zuhud-an ini, Hasan al-Basri mengatakan sebagaimana yang dikutip Harun Nasution bahwa : "Jauhilah dunia ini, karena ia sebenrnya serupa dengan ular, licin pada perasaan tangan, tetapi racunnya membunuh". ${ }^{13}$ Dapatlah dipahami bahwa menurut pandangan sufi, dunia dengan segala kehidupan materialnya adalah sumber kemaksiatan dan penyebab atau pendorong terjadinya perbuatan-perbuatan kejahatan yang menimbulkan kerusakan dan dosa. ${ }^{14}$

\footnotetext{
${ }^{10}$ Pengertian faqr dalam dunia sufi berfokus kepada sikap hidup yang tidak memaksa diri untuk mendapatkan sesuatu. Dengan kata lain, tidak menuntut lebih dari apa yang telah dimiliki atau melebihi dari kebutuhan primer.

${ }^{11}$ Ayat-ayat Alquran yang mengungkap pola hidup demikian adalah antara lain; QS. al-Baqarah (2): 173, QS. al-Nisa (4): 6, QS. al-Hasyr (59): 8.

${ }^{12}$ Mengenai pengertian zuhud ini, terdapat berbagai penafsiran, tetapi semuanya berkonotasi pada mengurangi dan kalau mungkin mengabaikan kehidupan duniawi dengan segala kenikmatannya.

${ }^{13}$ Harun Nasution, op. cit., h. 67.

${ }^{14}$ Ayat-ayat Alquran yang mengajak dan mendorong ke arah pola hidup sederhana dalam pengertian yang terbatas, memang banyak ditemukan dan sekaligus dijadikan sebagai dasar ajaran untuk bersikap hidup zuhud. Misalnya saja, QS. al-Nisa (4): 77, QS. Luqman (31): 33, QS. al-Hadid (57): 20, yang konotasinya mengajak dan menghimbau manusia agar jangan sampai diperdayakan oleh kemilau dan keasyikan kehidupan duniawi yang sifatnya sementara saja.
} 


\section{Sabar (الصبر 15}

Stasion sabar dalam dunia sufi menunjuk kepada pola hidup dan sikap pengendalian diri dan pengendalian sikap melalui latihan yang sungguh-sungguh. Menurut sufi, makna dan nilai kesabaran bermuara pada perolehan status yang tinggi dan mulia, serta kesejahteraan nikmat di akhirat. QS. al-Ra'd (13) : 24 Sehingga, ia merupakan salah satu perlengkapan dalam perjalanan calon sufi.

Sikap sabar, erat juga kaitannya dengan pengendalian emosi, sehingga calon sufi yang berada dalam stasiun ini harus mampu mengontrol dan mengendalikan nafsunya, mampu menerima cobaan-cobaan yang dialaminya, sambil menunggu datangnya pertolongan Tuhan.

\section{Tawakkal (التوكل) 16}

Stasion tawakkal dalam dunia sufi menunjuk kepada pola hidup menyerahakan diri sepenuhnya kepada Tuhan. Tawakkal, erat kaitannya dengan rencana dan usaha. Apabila rencana sudah matang dan usaha dijalankan dengan sungguh-sungguh sesuai rencana, hasilnya diserahkan kepada Tuhan. QS. Ali Imran (3): 159. dan QS. Thalaq (65): 3

Bagi kaum sufi, sikap tawakkal bukan hanya sekedar meyerahkan diri begitu saja, tetapi dalam segala sikap dan perbuatan dipasrahkannya kepada Tuhan di luar pintanya. Nasib apapun yang diterimanya menurut mereka adalah karunia Tuhan dan harus diterima secara senang dan ikhlas.

Dengan demikian, tawakkal adalah memasrahkan, mempercayakan dan menyerahkan segenap masalah kepada Allah sepenuhnya dengan ikhlas hanya bisa dicapai dengan sempurna melalui sikap ridha, rela dan menerima dengan senang dan lapang dada segala keputusandan perlakuan Allah kepada seorang hamba. Seseorang yang ta`wakkal kepada Allah berarti ia sudah membebaskan dirinya dari ketergantungan kepada makhluk.

\section{Ridha (الرضا)}

Stasion ridha dalam dunia sufi menunjuk kepada pola hidup menerima segala situasi dan kondisi dengan perasaan tenang dan senang. Calon sufi yang berada dalam stasiun ini, harus merasa senang menerima malapetaka dan merasa senang menerima nikmat. Setiap yang terjadi, disambutnya dengan hati terbuka, bahkan dengan rasa nikmat dan bahagia walau yang datang itu berupa bencana.

Sikap ridha yang disebutkan di atas, akan tumbuh melalui usaha demi usaha, perjuangan demi perjuangan mengikis habis segala perasaan gundah dan benci,

\footnotetext{
${ }^{15}$ Pengertian shabr dalam dunia sufi adalah konsukuen dan konsisten dalam melaksanakan semua perintah Allah. Rivay Siregar, op. cit., h. 120

${ }^{16}$ Pengertian tawakkal secara umum adalah pasrah dan mempercayakan secara bulat kepada Tuhan setelah melaksanakan suatu rencana dan usha, sedangkan pengertian tawakkal dalam dunia sufi adalah menyerah kepada qada' dan putusan dari Allah. Harun Nasution, op. cit., h. 68.

${ }^{17}$ Pengertian ridha dalam dunia sufi adalah perpaduan antara sabar dan tawakkal, yakni meninggalkan usaha dan menerima (tawakkal) dengan senang hati. Rivay Siregar, op. cit., h. 122.
} 
sehingga yang tinggal dalam hatinya hanya perasaan senang dan bahagia bergelora rasa cinta kepada Tuhan. Apapun yang datang dan pergi, ia tetap bahagia.

Stasion-stasion di atas, barulah merupakan tempat pensucian diri bagi orang yang memasuki jalan tasawuf. Karena itu, mereka yang berada di dalamnya masih berpredikat calon sufi atau zahid, di mana jalan yang dilaluinya seringkali diperhadapkan pada sikap-sikap abstrak yang dalam istilah tasawuf disebut ahwal. $^{18}$ yakni situasi mental kejiwaan yang diperoleh oleh calon sufi sebagai karunia Tuhan. Ketika keadaan mental itu telah terkondisi dan menjadi kepribadian, itulah yang disebut dengan al-hal.

Kalau maqamat (stasion-stasion) adalah tingkatan pelatihan dalam membina sikap hidup yang hasilnya dapat dilihat dari perilaku seorang, maka kondisi mental al-hal bersifat abstrak. Ia tidak dapat dilihat dengan mata, tetapi hanya dipahami dan dirasakan oleh seseorang yang mengalaminya. Oleh karena itu, tidak dapat diinformasikan melalui tulisan atau bahasa lisan.

\section{PUNCAK CAPAIAN PERJALANAN SUFISTIK}

Ketika calon sufi masih berada pada stasion ridha, lalu perasaan cintanya kepada Tuhan semakin tumbuh subur, mekar dan menggelora serta ia merasakan kehadiran Tuhan disisinya, maka sungguh ia telah tiba pada "puncak-puncak capaian sufistik". Dengan begitu, maka predikat yang disandangnya pun bukan lagi abid atau zahid, tetapi ia telah dianggap sebagai "sufi".

Kondisi kecintaan demikian dan perasaan akan kehadiran Tuhan pada diri sufi, diyakini sebagai suatu kenikmatan atau kebahagiaan hakiki yang terimplementasi dalam stasiun mahabbah, ${ }^{19}$ Yakni, seluruh jiwa dan segenap ekspresi sang sufi hanya diisi oleh rasa cinta dan rindu kepada Tuhan semata.

Menurut al-Sarraj mahabbah mempunyai tiga tingkatan

1. Cinta biasa, yaitu selalu mengingat Tuhan dengan zikir, selalu menyebut nama-nama Allah dan memperoleh kesenangan dalam berdialog dengan Tuhan.

2. Cinta orang siddik, ( الصديق )yaitu orang yang kenal dengan Tuhan pada kebesarannya, pada kekuasaannya, pada ilmunya, cinta yang seperti ini dapat

\footnotetext{
${ }^{18} \mathrm{Ahwal}$, jamak dari al-hal yang dalam pengertian tasawuf adalah keadaan mental yang merasuk ke dalam jiwa berupa perasaan takut, rendah hati, patuh, ikhlas, rasa berteman, gembira hati, syukur. Lihat Harun Nasution, op. cit., h. 63. Perasaan-perasaan seperti itu, merupakan manipestasi dari maqamat. Lihat A.J. Arberry, Sufism and Account of The Mistics of Islam, diterjemahkan oleh Bambang Herawan dengan judul, Tasawuf Versus Syariat, Cet. I (Jakarta: Hikmah, 2000), h. 103 ; Abd al-Razaq al-Qasyani, Isthilahat alSufiyah ( Mesir: al-Hay`ah al-Mishriyyah al-Ammah li al-Kitab, 1981), h. 26

${ }^{19}$ Mahabbah atau al-hub mengandung pengertian terpadunya seluruh kecintaan hanya kepada Tuhan, yang menyebabkan adanya rasa kebersamaan dengan-Nya. Yaitu,a) memeluk kepatuhan kepada Tuhan dan membenci sikap melawan padanya; b) menyerahkan seluruh diri kepada yang dikasihi c), mengosongkan hati dari dari segala-galanya kecuali dari diri yang dikasihi. Lihat Harun Nasution, op.cit., h. 70.Selanjutnya pandangan spesifik tentang mahabbah ini merupakan pangkal tolak kerohanian kehidupan para sufi yang dalam tasawuf dimana para pecinta belum dianggap sungguh-sungguh sebelum sampai ke tingkat "mabuk cinta" dan melupakan segala-galanya, selain kecintaannya kepada Tuhan.Lihat Abd Halim Mahmud, dalam pengantar kitab al-Luma` : al-Luma Wa Makanatuhu fi al-Tasawwuf al-Islamiy (Kairo: Maktabah al-Saqafah al-Diniyah, t.th),h. 9
} 
menghilangkan tabir yang memisahkan diri seseorang dari Tuhan sehingga dapat melihat rahasia-rahasia pada Tuhan.

3. Cinta orang yang Arif, ( العارف)yaitu orang yang tahu betul pada Tuhan. Cinta seperti ini timbul karena telah tahu betul pada Tuhan, dengan demikian yang dilihat dan dirasa bukan lagi cinta, tetapi diri yang dicintai, sehungga sifat-sifat yang dicintai masuk kedalam diri yang mencintai ${ }^{20}$.

Sufi yang mayshur dengan puncak capaian mahabbah, adalah Rabi'ah alAdawiyah. ${ }^{21}$ Bahkan kondisi kecintaannya kepada Tuhan yang semakin mesra dan tanpa pamrih itu menyebabkabnya ia menerima pancaran cahaya Tuhan, yang terimplementasi dalam stasion ma'rifah. ${ }^{22}$ Yakni, anugrah Tuhan kepada sufi yang dengan ikhlas dan sungguh-sungguh mencintai Tuhan, sehingga Tuhan mengungkapkan tabir dari pandangan sufi dan dengan terbukanya tabir itu, sufi pun dapat melihat keindahan Tuhan yang abadi.

Salah bentuk syair mahabbah-nya Rabi'ah adalah :

$$
\text { فارحم اليوم مذنبا قد اتاك الك الك }
$$

$$
\begin{aligned}
& \text { ياحب بيب القلب ما لي سـو الك } \\
& \text { يارجائى ور احتى وسرورى لي لئ }
\end{aligned}
$$

\section{Buah hatiku, hanya Engkaulah yang kukasihi \\ Beri Ampunlah pembuat dosa yang datang kehadiratmu \\ Engkaulah harapanku, kebahagianku dan kesenangannku \\ Hatiku telah enggan mencintai selain dari Engkau}

\footnotetext{
${ }^{20}$ Lihat Harun Nasution, ibid.

${ }^{21}$ Nama lengkapnya adalah Rabi'ah binti Ismail al-Adawiyah al-Qisiah, lahir di Bashrah tahun $95 \mathrm{H}$; wafat tahun $185 \mathrm{H}$ (713 M-801) dan dikuburkan di tempat kelahirannya pula. Ia hidup dalam keluarga miskin dan di usia remajanya Ayahnya meninggal, sehingga untuk melangsungkan hidupnya ia menjadi budak, di samping itu ia tidak berhenti beribadah dan berdoa di setiap malamnya. Rabi'ah memperoleh kemenangan kemerdekaan setelah tuannya menyaksikan suatu lentera yang bersinar terang tergantung tanpa tali di atas kepala Rabi'ah yang sedang berdoa ketia ia melakukan shalat malam, padahal di kamar itu tidak ada alat penerang. Suasana kemerdekannya itu, ia menolak segala pemberian dan bantuan materi dan mmenghindarkan dirinya dari kesenangan duaniawi. Bahkan kepada Tuhan pun, ia tidak meminta syurga. Ia rela masuk ke neraka asalkan Tuhan merestuinya. Saking cintanya kepada Tuhan, maka ia menolak semua tawaran kawin dengan alasan bahwa dirinya adalah milik Tuhan yang dicintainya, sehingga yang melamarnya haruslah minta izin dari Tuhan. Dikisahkan pula bahwa seorang pernah bertanya kepadanya: "Apakah engkau benci pada setan ?" dijawabnya "Tidak, cintaku kepada kepada Tuhan tidak meninggalkan ruang kosong dalam diriku untuk rasa benci pada setan. Disadur dari Harun Nasuition, loc. cit.; Ahmad Amin, Zuhr al-Islam (Beirut: Dar al-Kutub al-Arabiy, 1969), h. 154; Departemen Agama RI, Ensiklopedia islam (Jakarta: Dit. Bimpera, 19871988), h. 781; Abdul Mun'im Qandil, Rabi'ah al-Adawiyah; 'Azrau al-Bashrah al-Batul, diterjemahkan oleh Herry Muhammad dengan judul Figur Wanita Sufi; Perjalanannya Hidup dan Cintanya pada Allah (Surabaya: Pustaka Progressif, 1993), h. 23-30

${ }^{22}$ Ma'rifah berarti pengetahuan yang sangat jelas dan pasti tentang Tuhan yang diperoleh melalui sanubari. Karena jelas dan pastinya pengetahuan itu, menyebabkan sang sufi dapat melihat Tuhan dengan hatisanubarinya. Perlu diketahui bahwa dalam dunia tasawuf ; capaian al-Mahabbah selalu berdampingan dengan ma'rifah, karena nampaknya manivestsi dari al-mahabbah itu adalah tingkat pengenalan kepada Tuhan yang disebut ma'rifah. Terkait dengan itu, al-Gazali menyatakan bahwa al-mahabbah itu adalah pintu gerbang mencapai ma'rifah kepada Tuhan. Lihat Rivay Siregar, op. cit., h. 125. Lihat pula, Harun Nasution, op. cit., h. 75. Sementara itu, Ibn al-Faridh tidak membedakan antara al-mahabbah dan al-ma'rifah. Menurutnya, untuk memperoleh cinta Ialhi dan Ma'rifah adalah melalui pelepasan diri dari pengaruh rasio sehingga hati dapat leluasa untuk bekerja sendiri berdasarkan iradat Tuhan. Hal ini berarti, bahwa cinta itu bukan bersumber dari hari atau akal, tetapi cinta adalah sesuatu yang samawi dan sangat suci. Lihat Qamar Kailani, op. cit., h. 149.
} 
Sufi yang mayshur dalam sejarah tasawuf dengan capaian ma'rifah di samping Rabi'ah al-Adawiyah adalah Zunnun al-Mishry, ${ }^{23}$ yang menurutnya bahwa ia memperoleh ma'rifah karena kemurahan hati Tuhan. Sekiranya Tuhan tidak membukakan tabir dari mata hatinya, ia tidak akan dapat melihat Tuhan. Sebagai-mana disebut dalam literatur tasawuf bahwa sufi berusaha keras mendekatkan diri bawah dan Tuhan menurunkan rahmat-Nya dari atas. Dengan kata lain, ma'rifah datang ketika cinta sufi dari bawah dibalas Tuhan dari atas.

Lebih jauh mengenai stasiun ma'rifah ini, dalam literatur tasawuf dikatakan bahwa; (1) kalau mata yang terdapat di dalam hatisanubari manusia terbuka, mata kepalanya akan tertutup dan ketika itu yang dilihatnya hanya Tuhan; (2) ma'rifah adalah cermin. Kalau sufi melihat ke cermin itu yang akan dilihatnya hanyalah Tuhan; (3) yang dilihat sang sufi, baik di waktu tidur maupun sewaktu bangunnya hanyalah Tuhan; (4) sekiranya ma'rifah mengambil bentuk materi, cahaya yang disinarkannya gelap, semua orang yang memandangnya akan mati karena tak kuasa melihat kecermerlangan dan keindahannya. ${ }^{24}$

Tetapi sufi yang dapat menangkap cahaya ma'rifah dengan mata hatinya, akan dipenuhi kalbunya dengan rasa cinta yang mendalam kepada Tuhan. Tidak mengherangkan kalau sufi merasa tidak puas dengan ma'rifah saja, tetapi ia ingin berada lebih dekat lagi dengan Tuhan, yang terimplementasi dalam stasion ittihad. ${ }^{25}$ Yakni, mengalami penyatuan dengan Tuhan.

Sufi yang mayshur dalam sejarah tasawuf dengan capaian ittihad, adalah Abu Yazid al-Bustami, ${ }^{26}$ yang menurutnya bahwa sebelum sampai ke stasion ini terlebih dahulu seorang sufi harus mengalami fana dan baqa. ${ }^{27}$ Yakni, kehancuran jiwa atau hancurnya perasaan dan kesadaran tentang adanya tubuh kasar pada diri

${ }^{23}$ Nama lengkapnya adalah Abu al-Faiz ibn Ibrahim al-Mishri, lahir tahun 180 H/796 M di Mesir, wafat tahun 246 H/861 M dan dimakamkan di Giza. Sebagai tokoh sufi, ia terkenal ahli hypografi dan ahli kimia di seluruh dunia khususnya pada abad III hijriyah atau pertengahan abad IX Masehi. Disadur dari Ahmad Amin, op. cit., h. 160-161.

${ }^{24}$ Interaksi kecintaan sufi kepada Tuhan yang mengakibatkan tersingkapnya tabir dari-Nya, dapat diketahui dengan pemakaian kalbu sebagai sarana utama sang sufi. Yakni, hati sanubari yang berpusat di dada mempunyai tiga daya; (1) daya untuk mengetahui sifat-sifat Tuhan yang disebut qalb; (2) daya untuk mencintai Tuhan yang disebut ruh; (3) daya untuk melihat yang disebut sirr. Uraian lebih lanjut, lihat Harun Nasution "Tasawuf" dalam Budhy Munawar-Racham (ed), Kontekstualisasi Doktrin Islam dalam Sejarah (Cet.I; Jakarta: Paramadina, 1994), h. 169.

${ }^{25}$ Ittihad adalah suatu tingkatan dalam tasauf dimana yang yang dicintai dan yang mencintai telah menjadi satu. Harun Nasution, Filsafat, op. cit., h. 82

${ }^{26}$ Nama lengkapnya adalah Abu Yazid Thaifur Ibn Isa al-Bustami, lahir di Bistan (Persia) pada tahun $874 \mathrm{M}$ dan meninggal dalam usia 73 tahun. Ia dibesarkan dalam lingkungan keluarga yang taat beragama. Menurut beberapa sumber, sebelum al-Bustami menjadi sufi - telah terlebih dahulu mempelajari fiqih mazhab Hanafi, karena itu ia dikelompokkan dalam ahl al-ra'y yaitu aliran yang memberikan peranan sangat besar kepada akal (pemikiran) dalam memahami hukum Islam. Per-jalanannya sebagai seorang sufi didahuluinya dengan susah payah, kadang ia harus berada pada satu tingkat (maqam) bertahun-tahun lamanya untuk kemudian beralih ke tingkat kesufian yang lain. Disadur dari Harun Nasution, Islam Ditinjau dari Berbagai Aspeknya (Jakarta: UI Press, 1986), h. 84. Abu Bakar Aceh, Pengantar Sejarah Sufi dan Tasawuf (Solo: Ramadhani, 1990), h. 309.

${ }^{27}$ Fana dan al-Baqa adalah ketidak sadaran sufi akan dirinya dan alam sekitarnya sebagai usaha untuk mendapatkan kesatuan dengan Tuhannya untuk selama-lamanya. Harun Nasution, Falsafat, op. cit., h. 79 Bandingkan dengan Jumhuriyah Mishriyah al-Arabiyah Majma'ul Lughah al-Arabiyah, Al-Mu'jamal-Falsafiy (al-Qahirah : t.p, 1979), h. 11. 
sufi, sehingga yang tinggal hanyalah rohnya saja dan ketika itu ia dapat bersatu dengan Tuhan (ittihad), atau menunggal dengan Tuhan.

Ketika sang sufi sampai ke ambang pintu ittihad yang merupakan puncak akhir perjalanan sufistik, biasanya keluar ungkapan-ungkapan ganjil yang dalam

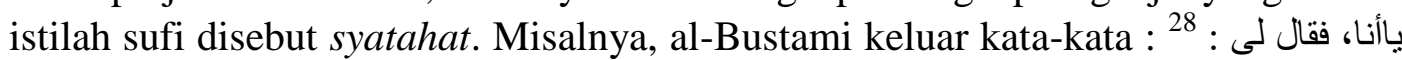

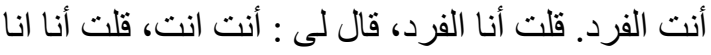

Artinya: Hai Aku” Ia berkata: Engkaulah yang satu”. Aku menjawab: “Akulah yang satu”. Ia berkata selanjutnya: "Engkau adalah Engkau”. Aku menjawab: Aku adalah Aku

Di sini, al-Bustami mengucapkan kata "Aku" bukan sebagai gambaran dari dirinya, tetapi gambaran Tuhan, karena ia telah bersatu dengan dirin-Nya. Dengan kata lain, al-Bustami dalam ittihad berbicara dengan nama Tuhan. Atau lebih tepat lagi "Tuhan berbicara" melalui lidah al-Bustami.

Sehabis sembahyang subuh, dalam zikir al-Bustami ia mengucapkan : إني إنا لإنا (Tidak ada Tuhan selain dari Aku maka sembahlah Aku” dan lebih lanjut ia mengatakan سبحانى، سبحانى، ما أعظم شأني (Maha Suci Aku, Maha Suci Aku, Maha Besar Aku”, dan orang yang turut mendengarnya menyangka dia gila dan ia pun mereka tinggalkan. Bahkan, setelah tiba di rumahnya; datanglah seorang mengetuk pintunya dan al-Bustami pun bertanya "siapa yang engkau cari"? orang itu menjawab "saya mencari al-Bustami", lalu dijawabnya : مر، فليس في " هergilah !,dirumah ini tak ada kecuali Allah Yang Maha Kuasa dan Maha Tinggi).

Selain itu ia juga pernah berkata: لله بي "Yang ada dalam baju ini hanya Allah.',

Kemanunggalan Tuhan dengan sufi dalam literatur Tasawuf, bukan saja stasiun ittihad yang terpakai, tetapi ditemukan pula istilah lain yang disebut dengan stasiun hulul, ${ }^{32}$ stasion ini diperkenalkan dan dialami oleh al-Hallaj. ${ }^{33}$

${ }^{28}$ Teks di atas, dapat dilihat dalam Harun Nasution, Falsafat, op. cit., h. 85.

${ }^{29}$ Ibid., h. 86.

${ }^{30}$ Lihat $i b d$.

${ }^{31}$ Lihat ibid

${ }^{32}$ Hulul, identik dengan itihad, yakni dua istilah kembar dalam tasawuf yang sama-sama dikategirikan sebagai stasion kemanunggalan sufi dengan Tuhannya.

${ }^{33}$ Al-Hallaj, Nama lengkapnya adalah Abu al-Mugis al-Husain bin Mansur bin Muhammad alBaidawi dilahirkan pada tahun $244 \mathrm{H}$ atau $858 \mathrm{M}$ di Thur (Persia) dan sejak usia belia sampai dewasanya ia banyak bergaul dan berguru dengan sufi misalnya Sahl Ibn Abdullah Tustari, Amr Makki, Junaid al-Bagdadi dll. Ia pernah berkhalwat di Masjidil Haram dalam keadaan duduk tanpa gerak kecuali untuk keperluan thawaf dan bersuci, sehingga ia tidak mempedulikan terik matahari dan hujan yang menyanyat tubuhnya. Karena pengalaman hululnya yang menurut penguasa bahwa ia mengakui dirinya sebagai Tuhan (انا الحق) maka ia dijebloskan ke penjara dan hukuman matipun menerpanya pada tanggal 24 Zulkaidah 309, tetesan darahnya yang mengalir membentuk huruf-huruf yang tertulis ana al-haq. Lihat B. Lewis, et.al. (Eds.), The Encyclopaedia of Islam, Vol. III, (EJ. Brill, Leiden, 1971), h. 99 Disadur dari Abu Bakar Aceh, op. cit., h.270273 dan Ibrahim Gazur Illahi, Mengungkap Misteri Sufi Besar Mansur al-Hallaj (Jakarta: Rajawali, 1986), h. 14; Ibrahim Basyuni, Nasy'at al-Tasawwuf al-Islam (Mesir: Dar al-Fikr, t.th), h. 183; Abd Qadir Mahmud, alFalsafah al-Sufiyyah fi al-Islam (Kairo: Dar al-Fikr, 1966), h. 361. 
Sebagaimana ittihad, hulul juga terjadi melalui fana dan baqa. Namun konteks al-fana al-Hallaj berbeda dengan al-fana bagi al-Bustami. Bagi alBustami, dalam keadaan fana dirinya sama sekali hancur dan yang ada di dalam dirinya hanyalah Tuhan. Sedangkan bagi al-Hallaj, diri tetap ada, yang terjadi adanya bersatunya sifat ketuhanan di dalam dirinya.

Menurut al-Hallaj, Tuhan kelihatannya mempunyai dua natur (sifat dasar) : ke Tuhanan (اللاهوت) dan kemanusiaan (الناسوت). Sebaliknya, manusia juga mempunyai sifat ketuhanan dalam dirinya. ${ }^{34}$ Natur dan sifat kemanusiaan inilah menyebabkan Tuhan dan manusia dapat bermanuggal.

Pengalaman al-Hallaj dalam hulul adalah ia mengakatan " (akulah yang benar), ${ }^{35}$ dimana bukanlah roh al-Hallaj yang mengucapkan kata itu, tetapi roh Tuhan yang mengambil tempat dalam dirinya.

Sebagai kelanjutkan dari paham hulul adalah stasiun wahdat al-wujud, ${ }^{36}$ sebagaimana yang diperkenalkan dan dialami oleh Ibn Arabiy. ${ }^{37}$ Menurutnya, nasut yang ada dalam hulul dirobah oleh Ibn Arabiy menjadi khalq (الخلق) "makhluk" dan lahut menjadi haq (الحق) "Tuhan". Khlaq dan haq adalah dua aspek bagi tiap sesuatu. Aspek yang sebelah luar disebut khalq dan aspek yang sebelah dalam disebut haq.

Ibn Arabiy memberikan pemahaman bahwa Tuhan yang diterangkan dalam stasion hulul, ingin melihat diri-Nya di luar diri-nya dan oleh karena itu dijadikan-Nya alam ini. Maka alam ini merupakan cermin bagi Tuhan. Di kala ia ingin melihat dirinya, Ia melihat kepada alam. Pada benda-benda yang ada dalam alam, karena dalam tiap-tiap benda itu terdapat sifat ketuhanan, Tuhan melihat diri-nya. Dari sini timbullah faham kesatuan. Yang ada dalam alam ini kelihatannya banyak, tetapi sebenarnya itu satu. Tak obahnya hal ini sebagai orang yang melihat dirinya dalam beberapa cermin yang diletakkan di sekelilingnya. Di dalam tiap cermin ia lihat dirinya; dalam cermin itu dirinya kelihatan banyak, tetapi dirinya sebenarnya satu.

Sehubungan dengan hal tersebut, satu hal yang harus diketahui bahwa para sufi sebenarnya tidak pernah mengakui dirinya Tuhan. Ini dapat dilihat dari dari

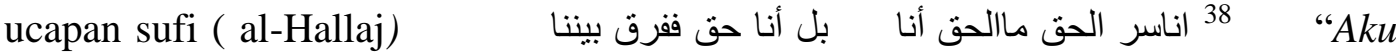

\footnotetext{
${ }^{34}$ Lihat QS. Al-Baqarah (2): 34 tentang perintah Tuhan kepada malaikat bersujud kepada Adam, karena pada diri Adam Allah menjelma sebagaimana Ia menjelma dalam diri Isa as.

${ }^{35}$ Harun Nasuition, Falsafat, op. cit., h. 91.

${ }^{36}$ Wahdat al-wujud berarti kesatuan wujud antara manusia dan Tuhan. Dengan begitu, istilah ini juga sebenarnya masih seidentik dengan ttihad dan hulul.

${ }^{37}$ Nama lengkapnya adalah Muhy al-Din Ibn Arabiy, lahir di Murchia (Spayol) tahun 1165 M. setelah selesai studi di Seville ia pindah ke Tunis di tahun 1194 M dan di sana ia masuk aliran sufi. Di tahun $1202 \mathrm{M}$ ia ke Mekkah dan meninggalkan Damaskus di tahun $1240 \mathrm{M}$. Jumlah buku yang dikarangnya menurut hitungan ada yang mengatakan tidak kurang dari 150 buah dan ada menyatakan 200 buah yang kesemuanya membahas tentang kesufian. Ia wafat di Damaskus pada tahun 638 H/1240 M. Lihat Hamka, Tasawuf Perkembangan dan Kemurniannya.(Jakarta: Pustaka Panjimas, 1993), h. 138; Harun Nasution, Falsafat, op. cit., h. 92

$$
{ }^{38} \text { Ibid., h. } 90
$$
}


adalah rahasia Yang Maha Benar, dan bukanlah yang Maha Benar itu aku, Aku hanya satu dari yang benar itu, maka bedakanlah antara kami”.

Dengan demikian dapat dipahami bahwa puncak perjalanan spritual menuju kebersamaannya dengan Tuhan bahkan menyatu dengan-Nya (ittihad) haruslah melewati berbagai tingkatan dan keadaan ruhani yang bervariasi. Berhubung puncak kesadaran mistik itu bersifat subyektif, maka jalan untuk mencapainya atau tingkat-tingkat kualitas penghayatan dan pengamalan serta metodologis yang ditempuh adalah beraneka ragam, tergantung kepada karakter psikologis dan kondisi pribadi seorang sufi.

\section{PENUTUP}

\section{A. Kesimpulan}

Berdasarkan uraian dan kajian tersebut di atas, maka dapat disimpulkan sebagai berikut:

1. Ajaran tasawuf pada hakekatnya adalah ekspresi keagamaan, ia merupakan komitmen moral dan iman dari orang-orang yang beragama secara saleh. Hal ini disebabkan, tasawuf dan ajarannya berfungsi untuk mewadahi dan menstabilkan komitmen moral orang yang beriman sehingga tasawuf memberikan tempat bagi kehidupan rohaniyah. Dengan rohani yang suci dan bersih, sang sufi memungkinkan dirinya untuk sampai pada puncak-puncak capaian sufistik, yakni mengadakan komunikasi, bahkan "menyatu" (ittihad) dengan Tuhannya. Dalam menggapai puncak-puncak capaian sufistik itu, memerlukan proses perjalanan yang sangat panjang dan melelahkan, karena harus melalui berbagai maqam dan hal.

2. Maqam adalah suatu tahap pencapaian ruhaniah dalam mendekat kepada Tuhan, yang merupakan hasil upaya bagi seorang sufi; sedangkan hal adalah suasana batiniah, yang senantiasa mengitari perasaan calon sufi dalam setiap maqam yang selalu bergerak naik setahap demi setahap sampai ke tingkat puncak perjalanannya yakni puncak capaian sufistik.

3. Metode perjalanan kepuncak capaian sufistik memiliki tingkat yang beragam, yakni mahabbah, ma'rifah, ittihad, hulul dan wahdat al-wujud. Untuk sampai pada tingkat-tingkat tersebut berbagai metodologis yang dilakukan para sufi. Dalam hal ini, metode yang dilakukan untuk sampai pada tingkat mahabbah dan ma'rifah adalah qalb - ruh - sirr. Sedangkan metode yang dilakukan untuk sampai pada tingkat itihad, hulul dan wahdat al-wujud adalah al-fana dan al-baqa.

\section{B. Implikasi}

Melalui kajian ini, dapat dipahami bahwa tasawuf berserta ajarannya adalah sebuah fenomena yang kaya sekaligus kompleks, ia mengandung berbagai dimensi yakni dimensi ritual, doktrinal dan etika. Begitupula halnya dengan agama Islam, tidak hanya mengatur hubungan dengan Allah swt., tetapi juga hubungan dengan manusia dan tasawuf mencakup permasalahn tersebut, hanya saja permasalahannya adalah sebagian orang memahami tasawuf dari satu aspek 
saja yakni aspek bathiniyah (rohaniyah ) tanpa memperhitungkan aspek lahiriahnya.

Selanjutnya, tasawuf juga mengingatkan manusia akan tanggung jawabnya mengenai apa yang dipikirkan dan yang dilakukan dalam hidup ini, oleh karenanya, maka wajib bagi kita untuk terus menerus berupaya mengungkap dan mengkaji ajaran yang terkandung dalam dunia tasawuf yang lebih sistimatis dan representatif. Sehingga terwujud " Manajemen Ruhani “ Dengan meniadakan dikotomi dalam menilai tasawuf dengan cara mengubah tasawuf dari gerakan spritual individual ke gerakan spritual kemasyarakatan.

Sesungguhnya tujuan akhir manusia adalah mengikat lingkaran rohaniahnya dengan Allah swt., sebagai hubungan yang selamanya benar. Oleh karena itu, dibutuhkan suatu kehidupan rohani untuk mendekatkan seorang hamba kepada Allah swt., hal ini banyak dilakukan dalam dunia tasawuf, sebab kehidupan yang hanya bersandar kepada kehidupan kebendaan adalah kehidupan yang semu, sedangkan kehidupan yang berdasarkan rohani dan fitri adalah kehidupan yang hakiki.

Oleh karena itu, menurut hemat penulis, tampaknya ajaran tasawuf mempunyai potensi yang sangat besar, sebab dewasa ini ajaran tasawuf dianut lebih humanistik, empirik dan fungsional, sehingga tasawuf mampu menawarkan pembahasan spritual, mengajak manusia mengenal dirinya sendiri, mengenal lingkungannya, dan mengenal Tuhannya. Hal ini merupakan pegangan hidup bagi manusia agar tidak terombang -ambing oleh badai kehidupan, ia menjadi penuntun hidup berakhlak al-karimah dan bermoral, sehingga dapat menunjukkan eksistensi manusia sebagai makhluk yang termulia di muka bumi ini. 


\section{DAFTAR PUSTAKA}

Al-Qur`an al-Karim.

Aceh, Abu Bakar. Pengantar Sejarah Sufi dan Tasawuf. Solo: Ramadhani, 1990

Amin, Ahmad. Zuhr al-Islam. Beirut: dar al-Kutub al-Arabiy, 1969

Arberry, A.J. Sufism and Account of The Mistics of Islam, diterjemahkan oleh Bambang Herawan dengan judul, Tasawuf Versus Syariat, Cet. I. Jakarta: Hikmah, 2000.

Al-Baqy, Muhammad Fu'ad Abd. al-Mu'jam al-Mufahras Li Alfaz al-Qur'an, Cet. III. Beirut: Dar al-Fikr, 1992.

Badawi, Abd al-Rahman. Syathahat al-Shufiyyah. Beirut: Dar al-Qalam, 1978.

Basyuni, Ibrahim. Nasy`at al-Tasawwuf al-Islam . Mesir: Dar al-Fikr, t.th.

As, Asmaran. Pengantar Studi Tasawuf (Edisi Revisi). Cet. II; Jakarta: Raja Grafindo Persada, 2002.

Departemen Agama RI, Ensiklopedia Islam. Jakarta: Dit. Bimpera, 1987-1988

Al-Gazali, Abu Hamid. Muqasyafah al-Qulub al-Muqarib ila Hadhrah 'Allam alGhuyub fi 'Ilm al-Tasawwuf, diterjemahkan oleh Irwan Kurniawan dengan judul " Menyingkap Hati Menghampiri Ilahi Ziarah Ruhani Bersama Imam al-Gazali" Cet. III; Bandung: Pustaka Hidayah, 2000.

-------. Ihya Ulum al-Din. Beirut: Dar al-Ma rifat, t.th

Hamka, Tasawuf Perkembangan dan Kemurniannya. Jakarta: Pustaka Panjimas, 1993

Hilal, Ibrahim. Al-Tasawwuf al-Islam Bayna al-Din wa al-Falsafah. Kairo: Dar alNahdah al-Arabiyah, 1979.

Hifni, Abd al-Mun`im. Mu`jam Musthalah al-Sufiyyah. Beirut: Dar al-Masirah, 1980.

Al-Hujwiri, Ali Usman al-Jullabi. Kasyf al-Mahjub: Risalah Persia Tertua Tentang Tasawuf, (Terj.) Abdul Hadi WM. Bandung: Mizan, 1993.

Hanbal. Ahmad Ibn. Kitab al-Zuhud. Beirut: Dar al-Nahdah al-Arabiyah, 1981.

Illahi, Ibrahim Gazur. Mengungkap Misteri Sufi Besar Mansur al-Hallaj. Jakarta: Rajawali, 1986.

Ibrahim, Muhammad Zaki, Abjadiyyah al-Tasawwuf al-Islamiy,diterjemahkan oleh Abdul Syukur AR. Dan A. Rivai Usman dengan judul" Tasawuf Salafi Menyucikan Tasawuf dari Noda-Noda. Cet. IV; Jakarta: al-Asyirah alMuhammadiyah,1989.

Jumhuriyah Mishriyah al-Arabiyah Majma'ul Lughah al-Arabiyah, Al-Mu'jam alFalsafiy. al-Qahirah : t.p, 1979.

Kailani, Qamar. Fiy al-tasawwuf al-Islam. Kairo: Dar al-Ma'arif, 1976.

Al-Kalabazi, al-Ta'aruf li Mazhab Ahl al-Tasawuf. Kairo: Maktabat al-Kulliyat alAzhariyah, 1969

Lewis, B., et.al. (Eds.), The Encyclopaedia of Islam, Vol. III, (EJ. Brill, Leiden, 1971).

Ma`luf. Louis, al-Munjid Fi al-Lughah wa al-A`lam. Beirut: Dar al-Masyriq, 1984

Mahmud, Abd Halim. Al-Luma wa Makanatuhu fi al-Tasawwuf al-Islamiy. Kairo: Maktabah al-Saqafah al-Diniyah, t.th 
Mahmud, Abd Qadir. Al-Falsafah al-Sufiyyah fi al-Islam . Kairo: Dar al-Fikr, 1966.

Al-Munawwar, Muhammad Ibn. Asrar al-Tauhid fi Maqamat al-Syaikh Abi Sa`id. Kairo: Dar al-Misriyyah li al-Ta lif wa Tarjamah, 1996.

Nasution, Harun. Falsafat dan Mistisisme dalam Islam, cet. VII. Jakarta: Bulan Bintang, 1990. . Islam Ditinjau dari Berbagai Aspeknya. Jakarta: UI Press, 1986 , "Tasawuf" dalam Budhy Munawar-Racham (ed), Kontekstualisasi Doktrin Islam dalam Sejarah. Cet.I; Jakarta: Paramadina, 1994.

Qandil, Abdul Mun'im. Rabi'ah al-Adawiyah; 'Azrau al-Bashrah al-Batul, diterjemahkan oleh Herry Muhammad dengan judul Figur Wanita Sufi; Perjalanannya Hidup dan Cintanya pada Allah. Surabaya: Pustaka Progressif, 1993

Al-Qasyani, Abd al-Razaq. Ishthilahat al-Sufiyah. Mesir: al-Hay`ah al-Mishriyyah al-Ammah li al-Kitab, 1981.

Siregar, Rivay. Tasawuf; dari Sufisme Klasik ke Neo-Sufisme, Cet. II. Jakarta: PT. RajaGrafindo Persada, 2000

Al-Shiddiqiy, Muhammad Ibn 'Alan. Dalil al-Falihin li Thuruq Riyadh alShalihin Riyadh:Daral-Ifta,tth. 